\title{
EPIDEMIOLOGICAL STUDIES OF THE NOVEL CORONAVIRUS (COVID-19) IN LIBYA
}

\begin{abstract}
Abdulmutalib Alabeed Allaq ${ }^{1}$, Email:alabeed119@gmail.com, Norrizah Jaafar Sidik*1, Email: norri536@uitm.edu.my, Aziyah Abdul-Aziz'Email: aziyah960@ uitm.edu.my; Abdul Mutalib
\end{abstract}

Alabeed Alkamil, Email: alabeed119@gmail.com; *Correspondence Author: norri536@uitm.edu.my, Faculty of Applied Sciences, Universiti Teknologi MARA, 40450 Shah Alam, Selangor Darul Ehsan, Malaysia.

Dr Asita Elengoe ${ }^{2}$,Email :asitaelengoe@yahoo.com; Faculty member of Biotechnology, Faculty of Science, Lincoln University College.

Esam Bashir Yahya ${ }^{3}$.Email: essam912013@gmail.com; School of Industrial Technology, Universiti Sains Malaysia, 11800 Penang, Malaysia

Muhanad Abdullah Abdulsamad ${ }^{4}$, Email: mohandabdulah9@gmail.com; Senior Lecturer, Department of Zoology, Faculty of Science, Sabratha University, 00218 Sabratha, Libya.

Article received 29.12.2020; $\quad$ Revised 12.2.2021; $\quad$ Accepted 2.20.2021

\begin{abstract}
The coronavirus disease 2019 (COVID-19) outbreak originated in Wuhan, China, as a series of acute atypical respiratory diseases. It has now spread to 221 countries.

Symptoms may appear 2-14 days after exposure to the virus. Though some people may be asymptomatic, the common symptoms of COVID-19 patients include, but not limited to, fever or chills, cough, shortness of breath or difficulty breathing, fatigue, muscle or body aches, headache, the new loss of taste or smell, sore throat, congestion or runny nose, nausea or vomiting, diarrhea.

Materials and Methods: The information was gathered from the review of relevant literature obtained from various databases such as Science Direct, Springer, PubMed, Google, and Google Scholar.

Mechanism of SARS-CoV-2 invasion into host cells: Coronaviruses are enveloped, positive-sense, singlestranded RNA viruses of $\sim 30 \mathrm{~kb}$. They infect a wide variety of host species. They are divided mainly into four genera; $\alpha, \beta, \gamma$, and $\delta$ based on their genomic structure. $\alpha$ and $\beta$ coronaviruses infect only mammals 28 .

Case Study in Libya: COVID-19 cases have affected the medical education system in Libya. Several medical schools were temporarily closed for several periods during the war, which resulted in delays in the graduation and medical education of thousands of medical students.

Medicine traditional of herbal plant: Medicinal plants have a fundamental role in our beliefs, especially among the elderly, and in light of the lack of adequate treatment and lack of necessary medicines. Some herbs may boost the immunity in the blood and increase antibodies, and it is unknown to scientists until now whether this might positively affect the body's immunity.

Conclusion: This study was aimed to provide information on epidemiological characterization and the spatial and temporal patterns of the COVID-19 pandemic in Libya. It is conclusively evident that the pandemic has affected the whole country, with incidence rates varying from one region to another. Meanwhile, the prevention and control of COVID-19 in Libya is still a tough fight.
\end{abstract}

Keyword : Coronavirus disease 2019, Symptoms, Libya, and Pandemic.

\section{INTRODUCTION}

The coronavirus disease 2019 (COVID-19) outbreak originated in Wuhan, China as a series of acute atypical respiratory diseases. It has now spread to 192 countries. This rapidly spread from Wuhan to other areas. The novel coronavirus was named as the severe acute respiratory syndrome coronavirus-2 (SARS-CoV-2, 2019-nCoV) due to its high homology $(\sim 80 \%)$ to SARS-CoV, which caused acute respiratory distress syndrome (ARDS) and increased mortality during 2002-2003 (Abd El-Aziz \& Stockand, 2020; @Abdel Rahman et al., 2020; Ahmadifar et al., 2019; Allaq et al., 2020a, 2020b; Amalraj et al., 2017; Badr et al.,
2020; Bashir et al., 2020; Belouzard et al., 2012; Bredan et al., 2020; Chan et al., 2020; Daw, ElBouzedi, et al., 2020; Daw, Zgheel, et al., 2020; Elhadi et al., 2020; Elhadi \& Msherghi, 2020; Group, 2020; Grzanna et al., 2005; Hassan et al., 2020; Horby et al., 2020; Kembuan et al., 2020; Ksiazek et al., 2003; Lashkari et al., 2020; Li et al., 2020; Lu, 2020; Millet \& Whittaker, 2014; Motlagh et al., 2020; Ou et al., 2020; Pan et al., 2020; Pastick et al., 2020; Rizk et al., 2020; Rouf et al., 2020; Tomazini et al., 2020; Walls et al., 2020; Wang et al., 2020; Wiersinga et al., 2020; F. Wu et al., 2020; Z. Wu \& McGoogan, 2020; Yahya 
et al., 2020a, 2020b; Yuki et al., 2020; Zheng et al., 2020; Zhou et al., 2020; Zou et al., 2020).

People with COVID-19 have had a wide range of symptoms reported - ranging from mild symptoms to severe illness. Symptoms may appear 2-14 days after exposure to the virus. Though some people may be asymptomatic, the common symptoms of COVID-19 patients include showed in Figure 1, but not limited to, fever or chills, cough, shortness of breath or difficulty breathing fatigue, muscle or body aches, headache, the new loss of taste or smell, sore throat, congestion or runny nose, nausea or vomiting, diarrhea. Severe cases of the epidemic can lead to pneumonia, multiple organ failure, and death (Ahmadifar et al., 2019).

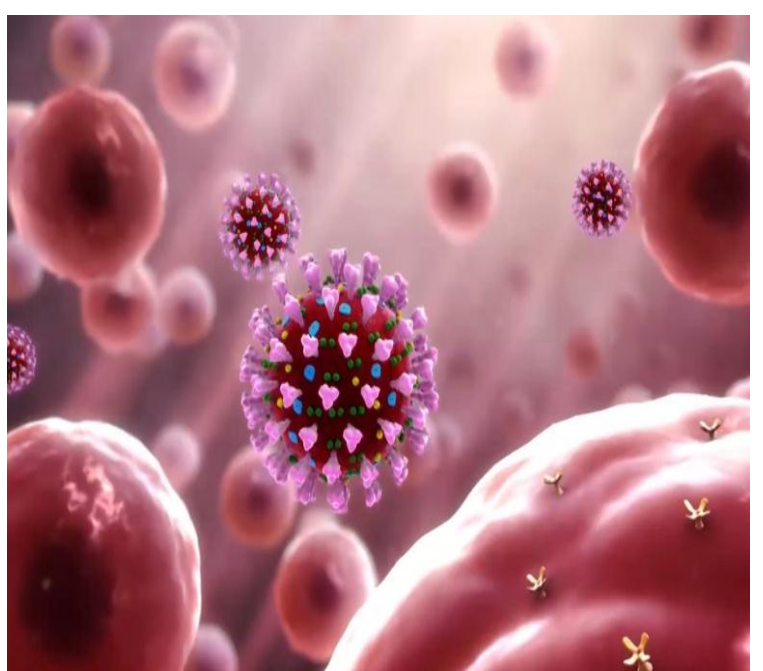

Fig. 1: coronavirus disease 2019 (COVID-19) https://www.warminsterclinic.co.uk/coronavirusprecautions

Globally, at least 1.7 million deaths have been directly attributed to COVID-19. Posing a significant international health threat, COVID-19 has drawn unprecedented attention from public health researchers worldwide, with more than 800 research articles published in academic journals within a year. There are also more than 300 epidemiologically and modeling preprints on COVID-19. Many of these articles seek to investigate the disease's epidemiological para-meters at various locations to disseminate critical information between both modelers and policy-makers for a timely control response to be imple-mented. This is particularly crucial as the current epidemic involves the new pathogenic (SARS-CoV-2), on which restricted knowledge exists of its infectivity and clinical profile (Abd El-Aziz \& Stockand, 2020; @Abdel Rahman et al., 2020; Ahmadifar et al., 2019; Allaq et al., 2020a, 2020b; Amalraj et al., 2017; Badr et al., 2020; Bashir et al., 2020; Belouzard et al., 2012; Bredan et al., 2020; Chan et al., 2020; Daw, El-Bouzedi, et al., 2020; Daw,
Zgheel, et al., 2020; Elhadi et al., 2020; Elhadi \& Msherghi, 2020; Group, 2020; Grzanna et al., 2005; Hassan et al., 2020; Horby et al., 2020; Kembuan et al., 2020; Ksiazek et al., 2003; Lashkari et al., 2020; Li et al., 2020; Lu, 2020; Millet \& Whittaker, 2014; Motlagh et al., 2020; Ou et al., 2020; Pan et al., 2020; Pastick et al., 2020; Rizk et al., 2020; Rouf et al., 2020; Tomazini et al., 2020; Walls et al., 2020; Wang et al., 2020; Wiersinga et al., 2020; F. Wu et al., 2020; Z. Wu \& McGoogan, 2020; Yahya et al., 2020a, 2020b; Yuki et al., 2020; Zheng et al., 2020; Zhou et al., 2020; Zou et al., 2020).

This disease could also be fatal. A growing number of patients with severe diseases have continued to succumb worldwide. Epidemiological studies have shown that mortalities are higher in the elderly population (Abd El-Aziz \& Stockand, 2020; @Abdel Rahman et al., 2020; Ahmadifar et al., 2019; Allaq et al., 2020a, 2020b; Amalraj et al., 2017; Badr et al., 2020; Bashir et al., 2020; Belouzard et al., 2012; Bredan et al., 2020; Chan et al., 2020; Daw, El-Bouzedi, et al., 2020; Daw, Zgheel, et al., 2020; Elhadi et al., 2020; Elhadi \& Msherghi, 2020; Group, 2020; Grzanna et al., 2005; Hassan et al., 2020; Horby et al., 2020; Kembuan et al., 2020; Ksiazek et al., 2003; Lashkari et al., 2020; Li et al., 2020; Lu, 2020; Millet \& Whittaker, 2014; Motlagh et al., 2020; Ou et al., 2020; Pan et al., 2020; Pastick et al., 2020; Rizk et al., 2020; Rouf et al., 2020; Tomazini et al., 2020; Walls et al., 2020; Wang et al., 2020; Wiersinga et al., 2020; F. Wu et al., 2020; Z. Wu \& McGoogan, 2020; Yahya et al., 2020a, 2020b; Yuki et al., 2020; Zheng et al., 2020; Zhou et al., 2020; Zou et al., 2020).

The incidence is much lower in children, and current medical management is mostly supportive with no targeted therapy available. Several drugs, including lopinavir-ritonavir, redelivery, hydroxychloroquine, and azithromycin, have been tested in clinical trials closed. Nevertheless, none of them have been proven to be a definite therapy yet. More therapies are being tested in clinical trials (Wu et al., 2020).

Furthermore, only a few African states have successfully implemented detection, prevention, and control measures. However, the COVID-19 pandemic poses a challenge for fragile African countries and those with well-functioning health systems. Until now, studies evaluating the epidemiological and spatial spread of the COVID19 pandemic in Africa are (Daw, El-Bouzedi, et al., 2020).

Libya is a developing country and less equipped to manage and control any pandemic due to the 
anarchy and loss of central control since 2011(Daw, Zgheel, et al., 2020) .Libyan healthcare infrastructure continues to deteriorate due to civil war, inadequate human and financial support, and inadequate health facilities. As stated by the Service Availability and Readiness Assessment (SARA-2017), conducted by the World Health Organization and Ministry of Health of Libya, 17 out of 97 hospitals are closed, and most hospitals operate at a low performance (Daw, Zgheel, et al., 2020). Only $40 \%$ of hospitals' inpatient beds are adequately functioning with an overall bed capacity of 15 per 10,000 , which is lower than the required target of 25 per 10,000 . Another concern is the lack of trained nurses. Moreover, Libya scored an average of $60 \%$ regarding the readiness of health emergency services, according to SARA2017 (Daw, Zgheel, et al., 2020).

\section{MATERIALS AND METHODS}

The information was gathered from the review of relevant literature obtained from various databases such as Science Direct, Springer, PubMed, Google, and Google Scholar.

Mechanism of SARS-CoV-2 invasion into host cells: Coronaviruses are enveloped, positive-sense, single-stranded RNA viruses of $\sim 30 \mathrm{~kb}$. They infect a wide variety of host species (Yuki et al., 2020 ). They are divided manily into four genera; $\alpha$, $\beta, \gamma$, and $\delta$ based on their genomic structure. $\alpha$ and $\beta$ coronaviruses infect only mammals (Yuki et al., 2020). Human coronaviruses such as $229 \mathrm{E}$ and NL63 are responsible for common cold and croup and belong to $\alpha$ coronavirus. Invariance, SARS$\mathrm{CoV}$, Middle East respiratory syndrome coronavirus (MERS-CoV), and SARS-CoV-2 are classified as $\beta$ coronaviruses (Yuki et al., 2020).

The virus's life cycle with the host consists of the following five steps: attachment, penetration, biosynthesis, maturation, and release. Once viruses bind to host receptors (attachment), they enter host cells through endocytosis or membrane fusion (penetration). Once viral contents are released inside the host cells, viral RNA enters the nucleus for replication. Viral mRNA is used to make viral proteins (biosynthesis). Then, new viral particles are made (maturation) and released. Coronaviruses consist of four structural proteins; Spike (S), membrane (M), envelope (E), and nucleocapsid (N) (Yuki et al., 2020).

Spike consists of a transmembrane trimetric glycoprotein protruding from the viral surface, which limited the diversity of coronaviruses and host tropism. Spike comprises two functional subunits; the $\mathrm{S} 1$ subunit is responsible for binding to the host cell receptor, and the S2 subunit is for the fusion of the viral and cellular membranes. Angiotensin-converting enzyme 2 (ACE2) was identified as a functional receptor for SARS(Millet \& Whittaker, 2014; Ou et al., 2020). The structural and functional analysis shows that the spike for SARS-CoV-2 is also bound to ACE2 (Millet \& Whittaker, 2014; Ou et al., 2020). ACE2 expression is high in the lung, heart, ileum, kidney, and bladder (Millet \& Whittaker, 2014; Ou et al., 2020). In the lung, ACE2 is much expressed on lung epithelial cells. Whether or not SARS-CoV-2 binds to an additional target needs further investigation. Following the binding of SARSCoV-2 to the host protein, the spike protein undergoes protease cleavage. A two-step sequential protease cleavage to activate spike protein of SARS-CoV and MERS-CoV was proposed as a model, consisting of cleavage at the S1/S2 cleavage site for priming and cleavage for activation at the $\mathrm{S}^{\prime} 2$ site, a position adjacent to a fusion peptide within the S2 subunit (Walls et al., 2020). After the cleavage at the S1/S2 cleavage site, S1 and S2 subunits remain non-covalently bound, and the distal $\mathrm{S} 1$ subunit contributes to the stabilization of the membrane-anchored S2 subunit at the prefusion state (Walls et al., 2020). Subsequent cleavage at the $\mathrm{S}^{\prime} 2$ site presumably activates the spike for membrane fusion via irreversible, conformational changes. The coronavirus spike is unusual among viruses because various proteases can cleave and activate it (Walls et al., 2020). The characteristic unique to SARS-CoV-2 among coronaviruses are the furoin cleavage site ("RPPA" sequence) at the $\mathrm{S} 1 / \mathrm{S} 2$ site. The S1/S2 site of SARS-CoV-2 was entirely subjected to cleavage during biosynthesis in drastic contrast to the SARS-CoV spike, which was incorporated into the assembly without cleavage (Walls et al., 2020).

Epidemiological data of COVID-19: At the beginning of the outbreak, COVID-19 cases were mostly observed among older adults (Ou et al., 2020; Walls et al., 2020; Zheng et al., 2020). As the outbreak continued, the number of cases among people aged 65 and older increased further, but some increases among children $(<18$ years) were observed. The number of male patients increased initially, but no significant gender difference was observed as the case number increased. The mean incubation period was 5.2 days. The combined case-fatality rate was $2.3 \%$ (Ou et al., 2020; Walls et al., 2020; Zheng et al., 2020).

Of all reported cases in Libya, this occupied only $1 \%$ of the total cases, even though this age group makes up $4 \%$ of Libya's population. Overall, the data suggested that children were less symptomatic 
than adults, as in Chinese reports. Among the children for whom complete information was available, only $67.08 \%$ developed fever, cough, or shortness of breath in table 1.

Compared to $93 \%$ of adults reported in the same time frame, between the ages of 25 and 75 years. The estimated hospitalization rate for children aged 1 to 17 was $14 \%$ at most(Elhadi et al., 2020; Elhadi
\& Msherghi, 2020). In contrast, infants accounted for the highest percentage of hospitalization (15$62 \%$ ), which was similar to the Chinese CDC data. Despite the overall favorable outcome for the pediatric population, several deaths have been reported in Libya of $1,43 \%$, and further information needs to be obtained (Elhadi et al., 2020; Elhadi \& Msherghi, 2020).

Table 1: Classification of COVID-19 patients

\begin{tabular}{|l|l|}
\hline Asymptomatic & No appreciable signs or symptoms \\
\hline Mild & $\begin{array}{l}\text { Symptoms of acute upper respiratory tract infection (fever, fatigue, } \\
\text { myalgia, cough, sore throat, runny nose, sneezing) or digestive } \\
\text { symptoms (nausea, vomiting, abdominal pain, diarrhea) }\end{array}$ \\
\hline Moderate & $\begin{array}{l}\text { Pneumonia (frequent fever, cough) with no obvious hypoxemia, chest } \\
\text { CT with lesions. }\end{array}$ \\
\hline Severe & Pneumonia with hypoxemia (SpO2 $<92 \%)$ \\
\hline Critical & $\begin{array}{l}\text { Acute respiratory distress syndrome (ARDS), may have shock, } \\
\text { encephalopathy, myocardial injury, heart failure, coagulation } \\
\text { dysfunction, and acute kidney injury. }\end{array}$ \\
\hline Moderate & $\begin{array}{l}\text { Symptoms of acute upper respiratory tract infection (fever, fatigue, } \\
\text { myalgia, cough, sore throat, runny nose, sneezing) or digestive } \\
\text { symptoms (nausea, vomiting, abdominal pain, diarrhea) }\end{array}$ \\
\hline Severe & $\begin{array}{l}\text { Pneumonia (frequent fever, cough) with no obvious hypoxemia, chest } \\
\text { CT with lesions. }\end{array}$ \\
\hline
\end{tabular}

Case Study in Libya: COVID-19 cases have affected the medical education system in Libya. Several medical schools were temporarily closed for several periods during the war, which resulted in delays in the graduation and medical education of thousands of medical students (Elhadi \& Msherghi, 2020).

A 73-year old Libyan male visited Saudi Arabia in February 2020. There, he encountered other people during a religious gathering. He returned to Tripoli, Libya, on March 5, 2020. His medical history included hypertension and type-2 diabetes mellitus (Bredan et al., 2020; Daw, El-Bouzedi, et al., 2020). Although his symptoms started with fever, cough, and generalized fatigue on March 18, he visited the Tripoli Central Hospital on March 22, where he was admitted with progressive dyspnoea, tachypnoea, and continued fever. On examination, his temperature was $39^{\circ} \mathrm{C}$, heart rate 75 beats $/ \mathrm{min}$, blood pressure 110/60 $\mathrm{mm} \mathrm{Hg}$, and oxygen saturation $95 \%$ on room air. On auscultation, decreased air entry bilaterally in the lower zone was noted. A high-resolution computed tomography (HRCT) showed multi-lobar and bilateral ground-glass opacities in both lungs, mostly in the mid to lower lungs, with peripheral subpleural distribution (appendix). Complete blood count results included: $0.70 \times 109 / \mathrm{L}$ lymphocyte count (reference range, $1.0-4.0 \times 109 / \mathrm{L}), 8.8 \times 10^{9} / \mathrm{L}$ white blood cell count, $168 \times 10^{9}$ platelet count (reference range, $150-400 \times 109 / \mathrm{L}$ ), and $11.9 \mathrm{~g} / \mathrm{dL}$ hemoglobin concentration. C-reactive protein concentration peaked on admission day at $168.4 \mathrm{mg} / \mathrm{L}$ (reference range, $<5 \mathrm{mg} / \mathrm{L}$ ), and he was isolated and appropriately treated with cefixime $400 \mathrm{mg}$ (tablet) every $24 \mathrm{~h}$ and azithromycin (500 $\mathrm{mg}$ on day one, followed by $250 \mathrm{mg}$ per day). As of April 4, the patient's condition had steadily improved. On examination, his temperature was $37^{\circ} \mathrm{C}$; heart rate 89 beats $/ \mathrm{min}$, blood pressure $140 / 70 \mathrm{~mm} \mathrm{Hg}$, and oxygen saturation $98 \%$ on room air. Besides, the patient was tested negative on April 4, 2020. Consequently, he was discharged and followed up accordingly (Bre dan et al., 2020; Daw, El-Bouzedi, et al., 2020).

Additionally, twenty-six of his family members were isolated until the RT-PCR assay tested negative on March 26 (Daw, El-Bouzedi, et al., 2020). Medicine traditional of herbal plant: Medicinal plants have a fundamental role in our beliefs, especially among the elderly, and in light of the lack of adequate treatment and lack of necessary medicines. Some herbs may a boosting the immunity in the blood and increase antibodies, and it is unknown to scientists until now whether this might positively affect the body's immunity (Daw, ElBouzedi, et al., 2020). Proving the ability of a herb or any other substance to enhance the body's immunity is one of the most complex issues, and in 
general, some types of herbs are known that they may contribute to enhancing the health of the immune system, but this is still uncertain, and there is still a need for more work. Thus, it is necessary to review the pote-ntial benefits of common medicinal plants and herbs(Allaq et al., 2020b).

Ginger: Dry ginger or ginger is used as a common ingredient in herbal medicine figure 2. Ginger is rich in anti-bacterial and anti-inflammatory properties is used as a popular home remedy for cough and cold in the form of tea, and it can help boost immunity naturally (Ahmadifar et al., 2019). Ginger an herbal medicinal product with broad antiinflammatory actions (Grzanna et al., 2005).

Ginger, the rhizome of the Zingiber officinale is commonly consumed dietary condiments (Rahmani, 2014), generally considered to be safe (Afzal et al., 2001), and used to cure various diseases (Figure 1). It also shows a role in cancer prevention by inactivating and activating various molecular pathways. role of ginger in diseases management via modulation of biological activities including anti-inflammatory and anti-oxidative activities, and regulation of genes mechanism of action(Silva \& Fernandes Júnior, 2010). Ginger plays a vital role in traditional Indian Ayurvedic medicine. It is also used as an ingredient in traditional Indian drinks (Mashhadi et al., 2013). Fresh ginger is one of the main spices used for making dishes, both vegetarian and non-vegetarian based foods. Indian traditional medicinal remedies especially for cough and asthma, consist of fresh ginger juice with a little juice of fresh garlic mixed with honey (ElGhorab et al., 2010). It also suggests of that 1-2 tea spoons of ginger juice with honey are a potent cough suppressant. Besides these ginger is very often used to cure many illness such as indigestion, tastelessness, loss of appetite, flatulence, intestinal, nausea, vomiting, allergic reactions, acute and chronic cough, common cold, fever, allergic rhinitis, sinusitis, acute chronic bronchitis, respiratory troubles, pain, headache, backache or any kind of muscular catch, painful tooth and swelled gum etc(kumar Gupta \& Sharma, 2014).

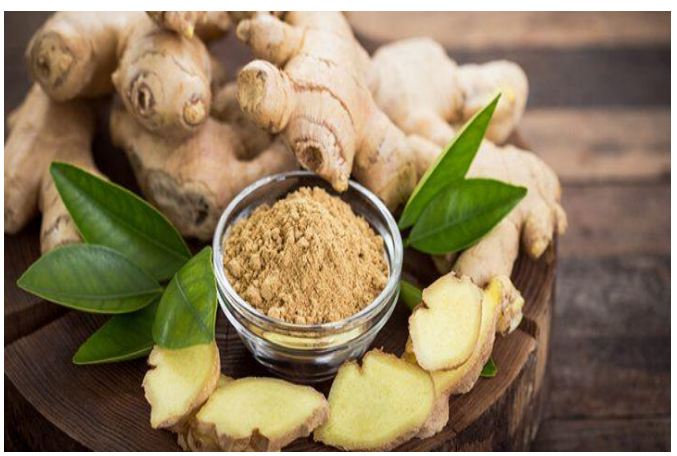

Fig. 2: Ginger
Turmeric: Turmeric a wide range of biological activities (Lal, 2012) (Figure 3) and is used in traditional medicines and is one of the components of herbal medicine (Lal, 2012). The Western world has consumed turmeric in tablet form (Silva \& Fernandes Júnior, 2010). It is locally consumed as a popular spice added to foods in India (Abdel Rahman et al., 2020). Often used to treat muscle pain or even as first aid in an injury. Turmeric contains many ingredients that can help fight disease (Amalraj et al., 2017). The essential oil inhibits the growth of various bacteria, parasites, and pathogenic fungi (Verma et al., 2018). Turmeric's protective effects on the cardiovascular system include lower cholesterol and inhibiting platelet aggregation (Verma et al., 2018) and Constituents of turmeric affects Alzheimer's disease. Extract of turmeric suppresses symptoms associated with arthritis (Sikha \& Harini, 2015) and its extract inhibit angiogenesis constituents can induce radio protection constituents to stimulate muscle regeneration (Andrade et al., 2018). Turmeric enhances wound healing and protects against pancreastitis (Mncwangi et al., 2012).

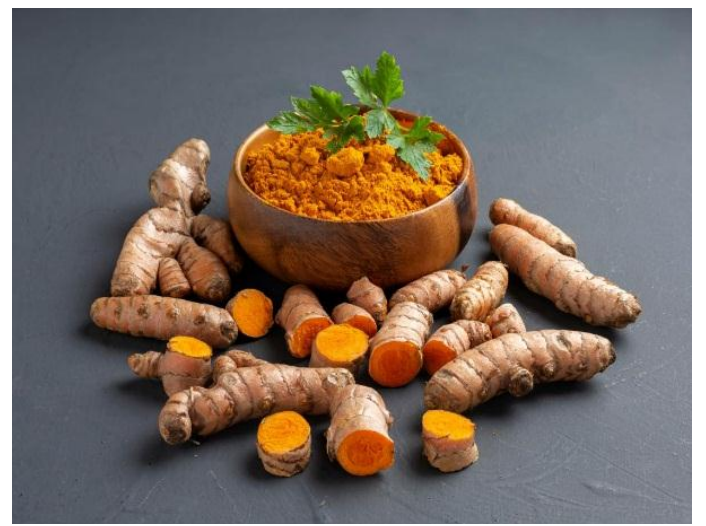

Fig. 3: Turmeric

Echinacea: Echinacea is an herb found primarily in the United States and southern Canada. It has many uses Figure 2 echinacea has properties that can relieve pain, reduce inflammation, and have antiviral and antioxidant effects. This makes it an ideal herb to support the immune system and boost its function (Kembuan et al., 2020). Also antifatigue agent, Immune System Effects of Echinacea antibacterial or antiviral activity through the immune system modulation(Kumar \& Ramaiah, 2011). Pharmacology and clinical properties of Echinacea species used medicinally (Block and Mead, 2003). Ecology and clinical properties treat symptoms of upper respiratory infections such as colds and influenza (Broadhurst et al., 2000), inflammatory conditions, including immune-modulating activities, 
antiviral activities, and antibiotic activities (Vimalanathan et al., 2009).

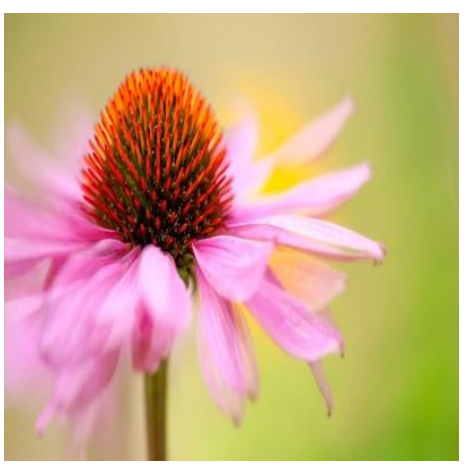

https://www.google.com/search?q=Echinacea\&tb $\mathrm{m}=$ isch\&ved=2ahUKEwidoZ3XtAhXJnEsFHTX QBGUQ2-cCegQIABAA\&oq=Echinacea\&gslcp= CgNpbWcQAzIECCMQJzICCAAyAggAMgIIDI CCAAyAggAMgIIADICCAAyAggAMgIIADoH CCMQ6gIQJ1DttAVY1rkFYI_IBWgBcAB4AIA BMogBMpIBATGYAQCgAQGqAQtnd3Mtd216 LWltZ7ABBMABAQ\&sclient=img\&ei=vpXsX5 3KE8m5rtoPtaCTqAY\#imgrc=IcadAwczyeNzFM Fig. 3: Echinacea

Garlic: Garlic has pharmaceutic effects Figure-4 and used to cure vast conditions including blood pressure and cholesterol, hepatoprotective, anthelmintics, anti-inflammatory (Tesfaye \& Mengesha, 2015), antioxidant, antifungal and wound healing, asthma, arthritis, sciatica, lumbago, backache (ElSaber Batiha et al., 2020), bronchitis, chronic fever, tuberculosis, rhinitis, malaria, obstinate skin fistula (Tesfaye \& Mengesha, 2015).Frost says garlic is a potent anti-microbial herb, especially in the gut. It is believed to be antiprotozoal, antibacterial, and antiviral These properties can help fight chest infections and respiratory infections (Motlagh et al., 2020). properties, including anticarcinogenic, antioxidant, antidiabetic, renoprotective, anti-atherosclerotic, antibacterial, antifungal, and anti-hypertensive activities in traditional medicines(ElSaber Batiha et al., 2020).

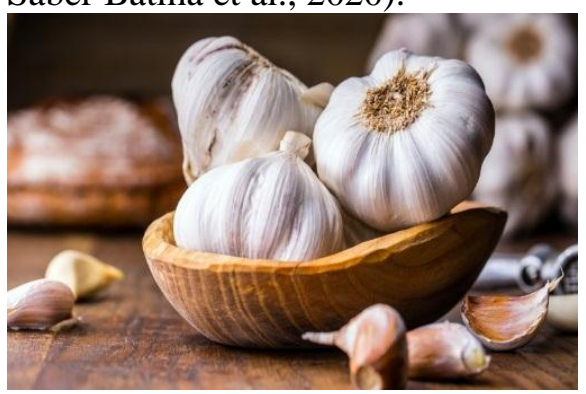

Fig. 4: Garlic

\section{Anti-viral drugs}

Although the US Food and Drug Administration (FDA) has approved only one drug to treat coronavirus disease in 2019 (COVID-19), scientists are currently testing several drugs (Abd El-Aziz \& Stockand, 2020). The US Food and Drug Administration has approved the antiviral drug remdesivir (Veklury) to treat adult COVID-19 patients, as well as children 12 years of age or older. Remdesivir may be prescribed to patients with Covid 19 whose condition requires hospitalization. It is given to the patient through a needle inserted into the skin (intravenously) (Badr et al., 2020). The FDA has approved the emergency use of a drug called baricitinib (Olumiant) (Bashir et al., 2020). The FDA states that baricetinib can be used with remdesivir to treat people admitted to hospital who need ventilators or additional oxygen after they have had COVID-19 (Bashir et al., 2020)Researchers are studying other potential treatments for COVID-19, including:

Antiviral drugs: In addition to remdesivir, other antivirals currently being tested include: favipiravir and merimepodib. Studies have found that combining lopinavir and ritonavir is not sufficent (Bashir et al., 2020).

Dexamethasone: The corticosteroid dexamethasone is one of the anti-inflammatory drugs researchers are currently studying to treat or prevent organ dysfunction and lung injuries caused by inflammation. Studies have found that it reduces deaths by nearly $30 \%$ in people dependent on ventilators and by nearly $20 \%$ in people who need additional oxygen (Tomazini et al., 2020). The US National Institutes of Health recommended this drug for people admitted to hospital with COVID19 who were put on mechanical ventilators or require additional oxygen. Other corticosteroids, such as prednisone, methylprednisolone, or hydrocortisone may be used if dexamethasone is not available. Dexamethasone and other corticesteroids may cause harm if given to less severe Covid 19 patients (Tomazini et al., 2020).

Unproven drugs: Researchers are studying several unproven drugs such as amlodipine and losartan. However effective these drugs are in treating or preventing COVID-19 is not yet known. Ivermectin and famotidine are not likely to help treat COVID-19 (Wiersinga et al., 2020).

Hydroxychloroquine and chloroquine: Previously, the FDA approved the use of these malaria drugs in emergencies during the COVID-19 pandemic. Nevertheless, the FDA withdrew its approval when graphical analyzes showed that these drugs are ineffective in treating COVID-19. These drugs can also cause serious problems (Pastick et al., 2020).

Medicines that protect against COVID-19: Researchers are studying the effectiveness of certain 
drugs in preventing COVID-19 patients before and after exposure to the virus.

\section{Conclusion}

This study was aimed to provide information on epidemiological characterization and the spatial and temporal patterns of the COVID-19 pandemic in Libya. It is conclusively evident that the pandemic has affected the whole country, with incidence rates varying from one region to another. Meanwhile, the prevention and control of COVID19 in Libya is still a tough fight. We have seen some European countries' health systems buckled under the surge of COVID-19 and appealed for help. The internal conflict in Libya has affected the national health care system immensely. There is a dearth of information on the capacity to provide care for critically ill patients in ICUs in Libya and a lack of accuracy and efficient tracing policy of COVID-19 infected cases. Hence, swift action to control the virus's further spread and improve response capabilities is urgently needed.

The study demonstrated the spatiotemporal characteristics and trends of COVID-19 in Libya, which is essential to better focus on preventive efforts. The country must scale up its containment and mitigation strategies - quarantine, isolation, and social distancing. Establishing functional infection prevention and control practices could help detect and contain the ongoing epidemic.

\section{REFERENCE}

Abd El-Aziz, T.M., \& Stockand, J.D., Recent progress and challenges in drug development against COVID-19 coronavirus (SARS-CoV2)-an update on the status. Infection, Genetics and Evolution 104327 (2020.

Abdel Rahman, A., El-Bouhy, Z., Wahbah, M., \& Ahmed, S., Effects of dietary turmeric and clove powder on growth and immune response of the Nile tilapia. Egyptian Journal of Aquatic Biology and Fisheries 24(5): 589-608 (2020).

Afzal, M., Al-Hadidi, D., Menon, M., Pesek, J., \& Dhami, M.S.I., Ginger: an ethnomedical, chemical and pharmacological review. Drug Metabolism and Drug Interactions 18(3-4): 159-190 (2001).

Ahmadifar, E., Sheikhzadeh, N., Roshanaei, K., Dargahi, N., \& Faggio, C., Can dietary ginger (Zingiber officinale) alter biochemical and immunological parameters and gene expression related to growth, immunity and antioxidant system in zebrafish (Danio rerio)? Aquaculture 507: 341-348 (2019).

Allaq, A.A., Sidik, N.J., Abdul-Aziz, A., \& Ahmed, I.A., Cumin (Cuminum cyminum L.): A review of its ethnopharmacology, phyto- chemistry. Biomedical Research and Therapy 7(9): 4016-4021 (2020a).

Allaq, A.A., Sidik, N.J., Abdul-Aziz, A., \& Ahmed, I.A., Cumin (Cuminum cyminum L.): A review of its ethnopharmacology, phytochemistry. Biomedical Research and Therapy 7(9): 4016-4021 (2020b).

Amalraj, A., Pius, A., Gopi, S. \& Gopi, S., Biological activities of curcuminoids, other biomolecules from turmeric and their derivatives-A review. Journal of Traditional and Complementary Medicine 7(2): 205-233 (2017).

Andrade, J.M., Faustino, C., Garcia, C., Ladeiras, D., Reis, C.P. \& Rijo, P., Rosmarinus officinalis L.: an update review of its phytochemistry and biological activity. Future Science OA 4(4): FSO283 (2018).

Badr, H.S., Du, H., Marshall, M., Dong, E., Squire, M.M. \& Gardner, L.M., Association between mobility patterns and COVID-19 transmission in the USA: a mathematical modelling study. The Lancet Infectious Diseases 20(11): 12471254 (2020).

Bashir, M.F., Ma, B., Komal, B., Bashir, M.A., Tan, D. \& Bashir, M., Correlation between climate indicators and COVID-19 pandemic in New York, USA. Science of The Total Environment, 138835 (2020).

Belouzard, S., Millet, J.K., Licitra, B.N. and Whittaker, G.R., Mechanisms of coronavirus cell entry mediated by the viral spike protein. Viruses 4(6): 1011-1033 (2012).

Block, K.I. and Mead, M.N., Immune system effects of echinacea, ginseng, and astragalus: a review. Integrative Cancer Therapies 2(3): 247-267 (2003).

Bredan, A., Benamer, H. and Bakoush, O., Analysis of geo-temporal evolution and modeling of the COVID-19 epidemic in Libya. MedRxiv (2020).

Broadhurst, C.L., Polansky, M.M. and Anderson R. A., Insulin-like biological activity of culi-nary and medicinal plant aqueous extracts in vitro. Journal of Agricultural and Food Chemistry 48(3): 849-852 (2020).

Chan, J. F.-W., Yuan, S., Kok, K.-H., To, K.K.W., Chu, H., Yang, J., Xing, F., Liu, J., Yip, C.C.Y. and Poon, R.W.-S., A familial cluster of pneumonia associated with the 2019 novel coronavirus indicating person-to-person transmission: a study of a family cluster. The Lancet 395(10223): 514-523 (2020).

Daw, M.A., El-Bouzedi, A.H., Ahmed, M.O. and Alejenef, A.A., The epidemiological characteristics of COVID-19 in Libya during the ongoing-armed conflict. MedRxiv (2020). 
Daw, M.A., Zgheel, F.A., El-Bouzedi, A. and M.O. Ahmed, Spatiotemporal Distribution of Tuberculosis and COVID-19 during the COVID-19 Pandemic in Libya. Disaster Medicine and Public Health Preparedness Pp. 1-12 (2020).

El-Ghorab, A.H., Nauman, M., Anjum, F.M., Hussain, S. and Nadeem, M., A comparative study on chemical composition and antioxidant activity of ginger (Zingiber officinale) and cumin (Cuminum cyminum). Journal of Agricultural and Food Chemistry 58(14): 8231 -8237 (2010).

Elhadi, M., Momen, A.A. and Abdulhadi, O.M.A., A COVID-19 case in Libya acquired in Saudi Arabia. Travel Medicine and Infectious Disease (2020).

Elhadi, M., and Msherghi, A., COVID-19 and civil war in Libya: the current situation. Pathog Glob Health, 114: 230-231 (2020).

El-Saber Batiha, G., Magdy Beshbishy, A., G Wasef, L., Elewa, Y. H. A., A Al-Sagan, A., El-Hack, A., Mohamed, E., Taha, A. E., M Abd -Elhakim, Y. and Prasad Devkota, H., Chemical constituents and pharmacological activities of garlic (Allium sativum L.): A review. Nutrients 12(3): 872 (2020).

Group, R.C., Dexamethasone in hospitalized patients with Covid-19-preliminary report. New England Journal of Medicine (2020).

Grzanna, R., Lindmark, L. and Frondoza, C.G., Ginger-an herbal medicinal product with broad anti-inflammatory actions. Journal of Medicinal Food 8(2): 125-132 (2005).

Hassan, R.A., Ali, S.M., Mohamed, A.H. and S.E Hamed, Antioxidant and Antimicrobial Activities of Echinacea purpurea L. Extracts. الانثطة المضادة للأكسدة و الميكروبات فى مستخلصات نبات . Journal of Agricultural Chemistry and Biotechnology 11(10): 279-283 (2020\}.

Horby, P., Lim, W. S., Emberson, J.R., Mafham, M., Bell, J.L., Linsell, L., Staplin, N., Brightling, C., Ustianowski, A. and Elmahi, E,. Dexamethasone in hospitalized patients with Covid-19-preliminary report. The New England Journal of Medicine (2020).

Kembuan, G., Lie, W. and Tumiomor, A., (2020). Potential usage of immune modulating supplements of the Echinacea genus for COVID-19 infection. Int. J. Med. Rev. Case Rep. 4(1): (2020).

Ksiazek, T.G., Erdman, D., Goldsmith, C.S., Zaki, S.R., Peret, T., Emery, S., Tong, S., Urbani, C., Comer, J.A. and Lim, W., A novel coronavirus associated with severe acute respiratory syndrome. New England Journal of Medicine 348(20): 1953-1966 (2003).

kumar Gupta, S. and Sharma, A., Medicinal properties of Zingier officinale Roscoe-A review. J. Pharm. Biol. Sci. 9: 124-129 (2014).

Kumar, K.M. and Ramaiah, S., Pharmacological importance of Echinacea purpurea. International Journal of Pharma and Bio Sciences 2(4): 304-314 (2011).

Lal, J., Turmeric, curcumin and our life: a review. Bull Environ Pharmacol Life Sci. 1(7): 11-17 (2012).

Lashkari, A., Najafi, F., Kavoosi, G. and Niazi, S., Evaluating the In vitro anti-cancer potential of estragole from the essential oil of Agastache foeniculum [Pursh.] Kuntze. Biocatalysis and Agricultural Biotechnology 27: 101727 (2020)

Li, Q., Guan, X., Wu, P., Wang, X., Zhou, L., Tong, Y., Ren, R., Leung, K.S.M., Lau, E.H.Y. and Wong, J.Y., Early transmission dynamics in Wuhan, China, of novel coronavirus-infected pneumonia. New England Journal of Medicine (2020).

Lu, H., Drug treatment options for the 2019-new coronavirus (2019-nCoV). Bioscience Trends 14(1): 69-71 (2020).

Mashhadi, N.S., Ghiasvand, R., Askari, G., Hariri, M., Darvishi, L. and Mofid, M.R., Antioxidative and anti-inflammatory effects of ginger in health and physical activity: review of current evidence. International Journal of Preventive Medicine 4(Suppl 1): S36 (2013).

Millet, J. K. and Whittaker, G.R., Host cell entry of Middle East respiratory syndrome coronavirus after two-step, furin-mediated activation of the spike protein. Proceedings of the National Academy of Sciences 111(42): 15214-15219 (2014).

Mncwangi, N., Chen, W., Vermaak, I., Viljoen, A. M. and Gericke, N., Devil's Claw-A review of the ethnobotany, phytochemistry and boilogiical activity of Harpagophytum procumbens. Journal of Ethnopharmacology 143(3): 755-771 (2012).

Motlagh, H.A., Safari, O., Selahvarzi, Y., Baghalian, A. and Kia, E., Non-specific immunity promotion in response to garlic extract suplemented diets in female Guppy (Poecilia reticulata). Fish \& Shellfish Immunology 97: 96-99 (2020).

Ou, X., Liu, Y., Lei, X., Li, P., Mi, D., Ren, L., Guo, L., Guo, R., Chen, T. and $\mathrm{Hu}$, J., Characterization of spike glycoprotein of SARS-CoV-2 on virus entry and its immune cross-reactivity with SARS-CoV. Nature Communications 11(1): 1-12 (2020). 
Pan, X., da Xu, H. Z., Zhou, W., Wang, L. and Cui, $X$., Identification of a potential mechanism of acute kidney injury during the COVID-19 outbreak: a study based on single-cell transcriptome analysis. Intensive Care Medicine 1: (2020).

Pastick, K.A., Okafor, E.C., Wang, F., Lofgren, S. M., Skipper, C.P., Nicol, M.R., Pullen, M.F., Rajasingham, R., McDonald, E.G. and Lee, T. C., Hydroxychloroquine and chloroquine for treatment of SARS-CoV-2 (COVID-19). Open Forum Infectious Diseases 7(4): ofaa130 (2020).

Rahmani, A.H., Active ingredients of ginger as potential candidates in the prevention and treatment of diseases via modulation of biological activities. International Journal of Physiology, Pathophysiology and Pharmacology 6(2): 125 (2014).

Rizk, J.G., Kalantar-Zadeh, K., Mehra, M.R., Lavie, C.J., Rizk, Y. and Forthal, D.N., Pharmaco-immunomodulatory therapy in COVID19. Drugs Pp. 1-26 (2020).

Rouf, R., Uddin, S.J., Sarker, D.K., Islam, M.T., Ali, E.S., Shilpi, J.A., Nahar, L., Tiralongo, E. and Sarker, S.D.,. Anti-viral potential of garlic (Allium sativum) and it's organosulfur compounds: A systematic update of preclinical and clinical data. Trends in Food Science \& Technology (2020).

Sikha, A. and Harini, A., Pharmacological activities of wild turmeric (Curcuma aromatica Salisb): a review. Journal of Pharmacognosy and Phytochemistry 3(5): (2015).

Silva, N.C.C. and Fernandes Júnior, A., Biological properties of medicinal plants: a review of their antimicrobial activity. Journal of Venomous Animals and Toxins Including Tropical Diseases 16(3): 402-413 (2010).

Tesfaye, A. and Mengesha, W., Traditional uses, phytochemistry and pharmacological properties of garlic (Allium Sativum) and its biological active compounds. Int. J. Sci. Res. Eng. Technol. 1: 142-148 (2015).

Tomazini, B.M., Maia, I.S., Cavalcanti, A.B., Berwanger, O., Rosa, R.G., Veiga, V.C., Avezum, A., Lopes, R.D., Bueno, F.R.and Silva, M.V.A.O., Effect of dexamethasone on days alive and ventilator-free in patients with moderate or severe acute respiratory distress syndrome and COVID-19: the CoDEX randomized clinical trial. Jama 324(13): 13071316 (2020).

Verma, R.K., Kumari, P., Maurya, R.K., Kumar, V., Verma, R.B. and Singh, R.K., Medicinal properties of turmeric (Curcuma longa L.): A review. IJCS 6(4): 1354-1357 (2018).

Vimalanathan, S., Arnason, J.T. and Hudson, J.B., Anti-inflammatory activities of Echinacea extracts do not correlate with traditional marker components. Pharmaceutical Biology 47(5) 430-435 (2009).

Walls, A.C., Park, Y.-J., Tortorici, M.A., Wall, A., McGuire, A.T. and Veesler, D., Structure, function, and antigenicity of the SARS-CoV-2 spike glycoprotein. Cell (2020).

Wang, K., Chen, W., Zhou, Y.-S., Lian, J.-Q., Zhang, Z., Du, P., Gong, L., Zhang, Y., Cui, H.-Y. and Geng, J.-J., SARS-CoV-2 invades host cells via a novel route: CD147-spike protein. BioRxiv (2020).

Wiersinga, W.J., Rhodes, A., Cheng, A.C., Peacock, S.J. and Prescott, H.C., Pathophysiology, transmission, diagnosis, and treatment of coronavirus disease 2019 (COVI D-19): a review. Jama 324(8): 782-793 (2020)..

Wu, F., Zhao, S., Yu, B., Chen, Y.-M., Wang, W., Song, Z.-G., Hu, Y., Tao, Z.-W., Tian, J.-H. and Pei, Y.-Y., A new coronavirus associated with human respiratory disease in China. Nature 579(7798): 265-269 (2020).

$\mathrm{Wu}, \mathrm{Z}$. and McGoogan, J.M., Characteristics of and important lessons from the coronavirus disease 2019 (COVID-19) outbreak in China: summary of a report of 72314 cases from the Chinese Center for Disease Control and Prevention. Jama 323(13): 1239-1242 (2020).

Yahya, E.B., Abdulsamad, M.A., Allaq, A.A., Abdoallah, T. and Ermese, E., The Effect of Natural and Petroleum Based Materials on the Growth Rate and Antibiotic Sensitivity of Pseudomonas aeruginosa. International Journal for Research in Applied Sciences and Biotechnology 7(5): 295-298 (2020a).

Yahya, E.B., Abdulsamad, M.A., Allaq, A.A., Abdoallah, T. and Ermese, E., The Effect of Natural and Petroleum Based Materials on the Growth Rate and Antibiotic Sensitivity of Pseudomonas aeruginosa. International Journal for Research in Applied Sciences and Biotechnology 7(5): 295-298 (2020b).

Yuki, K., Fujiogi, M. and Koutsogiannaki, S., COVID-19 pathophysiology: A review. Clinical Immunology Pp. 108427 (2020).

Zheng, M., Gao, Y., Wang, G., Song, G., Liu, S., Sun, D., Xu, Y. and Tian, Z., Functional exhaustion of antiviral lymphocytes in COVID-19 patients. Cellular \& Molecular Immunology 17(5): 533-535 (2020)..

Zhou, P., Yang, X.-L., Wang, X.-G., Hu, B., Zhang, L., Zhang, W., Si, H.-R., Zhu, Y., Li, B. 
and Huang, C.-L., A pneumonia outbreak associated with a new coronavirus of probable bat origin. Nature 579(7798): 270-273 (2020).

Zou, X., Chen, K., Zou, J., Han, P., Hao, J. and Han, Z., Single-cell RNA-seq data analysis on the receptor ACE2 expression reveals the potential risk of different human organs vulnerable to 2019 -nCoV infection. Frontiers of Medicine Pp. 1-4 (2020). 